\title{
Filogenética Molecular de Peces del Complejo Midas Cichlidae que habitan lagos y lagunas de Nicaragua, utilizando el gen COI
}

\author{
Lucia Páiz-Medina* y Jorge A. Huete-Pérez**
}

Recibido: octubre 2012/ Aceptado: diciembre 2012

Las lagunas cratéricas de Nicaragua se consideran verdaderos "laboratorios" naturales de investigación debido a que son geológicamente jóvenes y por su pequeña dimensión, lo que permite el estudio de procesos evolutivos y de especiación. En estas lagunas se encuentran especies endémicas (familia Cichlidae) que representan recursos valiosos para estudios de especiación, incluyendo la velocidad y fuerzas con las que el aislamiento geográfico, la selección natural y sexual provocan la diversificación fenotípica y, finalmente, la especiación misma. Los peces de la familia Cichlidae han sido objeto de mucha controversia debido a que morfológicamente es difícil diferenciarlos y se requieren de nuevas herramientas moleculares para descifrar las diferencias a nivel genético y entender mejor los procesos de especiación de este fascinante grupo de peces. En este estudio se utilizó el gen Citocromo Oxidasa I, COI, para determinar las relaciones filogenéticas entre los peces del Complejo presente en lagos y lagunas de Nicaragua. El COI ha sido propuesto como "código de barras" genético y como técnica ha sido estandarizada para animales. Este trabajo es parte de una investigación más grande que se enmarca en el Proyecto "DNA Barcoding de la biodiversidad nicaragüense” y se realiza en el Centro de Biología Molecular de la Universidad Centroamericana. Con este estudio se ha logrado determinar que:

1 Este trabajo de tesis de Lucia Páiz, realizado en la Universidad Centroamericana bajo la tutoría de Verónica Diaz (UNAN-León) y Jorge A. Huete-Pérez, fue premiado con el primer lugar del Premio Nacional al Talento Científico Joven 2011 de la Academia de Ciencias de Nicaragua.

* Centro de Biología Molecular, Universidad Centroamericana, Rotonda Rubén Dario, 500 mts al oeste, Apto. Postal 69. Managua, Nicaragua. Tel: 278-3923 Ext.1189. Correo electrónico: luciapaiz@uca-cbm.org

** Dr. Jorge A. Huete-Perez is director of the Molecular Biology Center at UCA and a research scientist at Ocean Genome Legacy, MA. , USA. Correo electronic: jorgehuete@uca-cbm.org 
(1) el gen COI discrimina entre especies de diferentes lagunas, (2) las relaciones entre las especies Midas Cichlidae son complejas y es necesario más de un gen para obtener resultados concluyentes, (3) las especies fundadoras de las lagunas cratéricas provienen del lago de Nicaragua, (4) en las lagunas habitan más de una especie del Complejo Midas Cichlidae y (5) se infiere que la especiación simpátrica es el mecanismo evolutivo que ha conducido a la creación de estas especies, confirmando la hipótesis de otros autores y aportando nuevos elementos sobre la complejidad filogenética de los cíclidos de Nicaragua.

Palabras clave: DNA Barcode / Gen COI/Complejo Midas Cichlidae / Nicaragua/ Relaciones filogenéticas

\section{Introducción}

Las lagunas cratéricas de Nicaragua se presentan como laboratorios naturales de evolución que poseen la ventaja de ser pequeñas -al contrario de los grandes lagos africanos-y recientes lo que permite colectar muestras en prácticamente todas las localidades, aun con la dificultad de acceso en algunas zonas, haciendo de esta forma las investigaciones más accesibles. En cada una de estas lagunas se encuentran diferentes especies endémicas, lo que permite estudiar los procesos de especiación de una forma, única además de la velocidad y fuerzas con las que el aislamiento geográfico, la selección natural y sexual provocan la diversificación fenotípica y la especiación (Elmer et al 2010b).

En Nicaragua existe un grupo de peces que habitan lagos y lagunas cratéricas, pertenecientes a la familia Cichlidae. Desde los primeros intentos de clasificación estas han sido objeto de discusión, debido a que algunos son muy parecidos morfológicamente y es difícil diferenciarlos y clasificarlos. Se pensaba que solamente existía una especie y que presentaba diferentes formas.

La especiación es un tema amplio y complejo. La especiación simpátrica, ha sido objeto de mucha crítica porque hasta hace poco era la menos sustentada por evidencia, pero en los últimos años se ha fortalecido con el uso de marcadores de ADN.

En este estudio se utilizó como marcador genético el gen COI para identificar y relacionar las diferentes especies de mojarras. El gen COI fue propuesto como "Código de Barras" genético en el 2003 por investigadores de la Universidad Guelph en Ontario, Canadá. Es una técnica que ya ha sido estandarizada para animales, y en peces se encuentran varios estudios en los que se ha podido identificar especies e inferir sobre la relación filogenética. Este forma parte de una investigación más amplia que se enmarca en el Proyecto "DNA Barcoding de la biodiversidad nicaragüense realizado por el Centro de Biología Molecular de la Universidad Centroamericana.

Comprender las relaciones filogenéticas y las causas posibles del proceso de especiación de estas especies es importante para la conservación de las mismas, dado que siendo únicas, se encuentran amenazadas por la introducción de especies exóticas como la tilapia y por la intensa actividad antropogénica.

Con este estudio se espera contribuir a responder las interrogantes planteadas 
por los primeros investigadores y la comunidad científica acerca de la correcta clasificación de la mojarra, relaciones filogenéticas e inferir acerca del proceso de especiación de las especies del Complejo. Actualmente no hay investigadores nacionales trabajando en este tipo de estudios, por lo que con este trabajo se promueve la investigación nacional, utilizando técnicas modernas y abordando temas de actualidad y de importancia para Nicaragua.

\section{Materiales y Métodos}

La investigación se realizó en dos etapas principales: (1) La recolección de muestras en lagos y lagunas de Nicaragua, y (2) los procedimientos experimentales de laboratorio en el Centro de Biología Molecular de la Universidad Centroamericana.

\section{Recolección de Muestras}

Las muestras de peces se colectaron en el período Enero-Marzo 2008, con la colaboración de los expertos Matthias Geiger (Zoologische Staatssammlung München) y Jeffrey McCrary (FUNDECI-GAIA). Se muestrearon un total de 14 sitios entre lagunas, lagos y ríos. (Figura $1 \mathrm{~A}, \mathrm{~B}$ ).

Figura 1. A. Lagunas muestreadas B. Sitios muestreados en el Lago de Nicaragua, Managua y Río San Juan. (Tomado de Google Earth 2011)
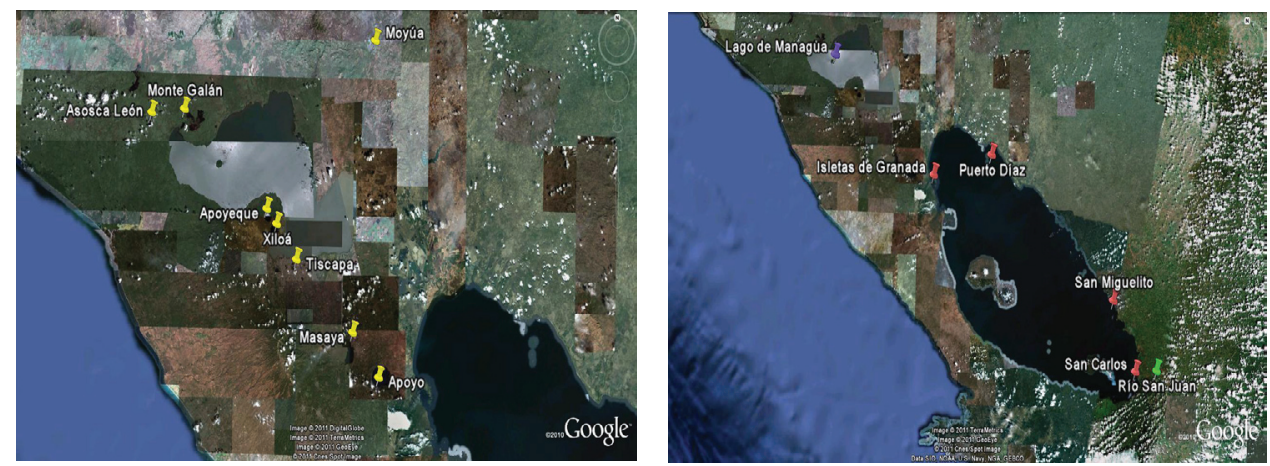

Rio San Juan. (Tomado de Google Earth 2011)

Para la captura de los peces se utilizaron redes de agalla y arpón. Los peces se sacrificaron utilizando anestesia comercial, y se tomó como muestra una aleta pectoral que se colocó en tubos con etanol 100\%, para luego conservarse en refrigeración a $-20^{\circ} \mathrm{C}$. Cada espécimen fue debidamente fotografiado y se anotaron datos de campo como código (siendo 519 la muestra No.1 y 820 la muestra No.239), familia, localidad, coordenadas geográficas. Cuando fue posible se les identificó de acuerdo a las descripciones más recientes de especies del Complejo; en caso contrario, se rotuló a los individuos como A. sp o A. citrinellus. Las muestras de aleta se encuentran preservadas en el Centro de Biología Molecular de la UCA, debidamente rotuladas y los individuos colectados están almacenados permanentemente en la Bavarian State Collection en Munich, Alemania. 


\section{Análisis de laboratorio}

Extracción de ADN. El ADN genómico se extrajo a partir de tejido de la aleta pectoral. Se utilizaron dos diferentes métodos: Extracción orgánica (protocolo modificado de de Lopera-Barrero et al, 2008) y kit comercial Phire ${ }^{\circledR}$ Animal Tissue Direct PCR

Para comprobar la condición del ADN obtenido se realizó electroforesis en geles de agarosa al $0.8 \%$ utilizando buffer TAE $1 \mathrm{X}$. El ADN se tiñó con bromuro de etidio $(10 \mathrm{mg} / \mathrm{ml})$. Como referencia se usó un marcador de peso molecular de $1 \mathrm{~Kb}$ (New England Biolabs). El ADN se visualizó bajo luz ultravioleta (UV) en un transluminador.

Amplificación por PCR. El gen COI se amplificó utilizando la enzima Phire Hot Start II siguiendo las recomendaciones del fabricante con algunas modificaciones: 2X Phusion Phire Animal Tissue PCR Buffer (incluye dNTP's y $\mathrm{MgCl}_{2}$ ), 0.25 microM cada primer (IDT, FishF1-5' TCA ACC AAC CAC AAA GAC ATT GGC AC 3', FishR1-5' TAG ACT TCT GGG TGG CCA AAG AAT CA 3'), y $0.8 \mathrm{U}$ de Phire Hot Start II en un volumen final de $20 \mu \mathrm{L}$. Se utilizó un termociclador ABI 2720 bajo las siguientes condiciones: primer ciclo de desnaturalización de ADN a $98^{\circ} \mathrm{C}$ por $30 \mathrm{seg}, 25$ ciclos de desnaturalización a $98^{\circ} \mathrm{C}$ por $5 \mathrm{seg}$, hibridación a $62^{\circ} \mathrm{C}$ por $40 \mathrm{~s}$, y elongación a $72^{\circ} \mathrm{C}$ por $20 \mathrm{seg}$, con una extensión final de $72^{\circ}$ C por 5 min.

Los productos de PCR migraron en geles de agarosa al $1.4 \%$ en una cámara de electroforesis utilizando buffer TAE $1 \mathrm{X}$ y luego se tiñeron con bromuro de etidio $(10 \mathrm{mg} / \mathrm{ml})$. Como referencia se usó un marcador de peso molecular de $100 \mathrm{pb}$ (New England Biolabs). El ADN se visualizó bajo luz ultravioleta (UV) en un transluminador.

Secuenciación. Las muestras se secuenciaron directamente usando el Big DyeTerminator Kit (ABI). A las muestras producto de la PCR convencional seles realiza cycle sequencing siguiendo las instrucciones del fabricante con las siguientes modificaciones: $1 \mu \mathrm{l}$ Big Dye Terminator (mezcla de polimerasa y dideoxinucleótidos flourescentes), $2 \mu$ de buffer Big Dye Terminator, $40 \mathrm{mM}$ Primer, $2.5 \mu \mathrm{l}$ de producto de PCR y $3.7 \mu \mathrm{l}$ de agua destilada, luego se realizó cycle sequencing utilizando el siguiente programa: desnaturalización inicial $96^{\circ} \mathrm{C}$ por $1 \mathrm{~min}, 25$ ciclos de desnaturalización a $96^{\circ} \mathrm{C}$ por $10 \mathrm{seg}$, hibridación a $50^{\circ} \mathrm{C}$ por $5 \mathrm{seg}$ y elongación a $60^{\circ} \mathrm{C}$ por $4 \mathrm{~min}$, a una temperatura de almacenaje de $4^{\circ} \mathrm{C}$.

Los productos resultantes de las reacciones del 'cyclesequencing' se purificaron utilizando un protocolo estándar Etanol/Acetato de Amonio. Luego el ADN se resuspendió en $10 \mu \mathrm{l}$ de formamida y se colocó en una placa de secuenciación. Se desnaturalizó por $5 \mathrm{~min}$, para posteriormente ser analizados en un Analizador genético ABI 3130 siguiendo las recomendaciones del fabricante.

Debido a que la secuenciación es una técnica en la que se invierten reactivos de alto costo, se decidió secuenciar únicamente 70 muestras del total. Además, este estudio es parte de un proyecto cuyos objetivos son utilizar las muestras que se conservan en el CBM-UCA en análisis posteriores en los que se incluirán el total de las muestras. 


\section{Análisis de las secuencias}

Basic Local Alignment Search Tool (BLAST). Para conocer si la secuencia que se obtuvo correspondía al gen de interés se utilizó la herramienta Basic Local Alignment Search Tool (BLAST) disponible en el sitio web de el National Center for Biotechnology Information (http://blast.ncbi.nlm.nih.gov/Blast.cgi). El BLAST encuentra las regiones de similitudes entre las secuencias locales. El programa compara secuencias de nucleótidos y de esta comparación se obtuvieron todas aquellas secuencias que son similares a la que se sometió al análisis.

Edición y alineamiento de las secuencias. La edición de las secuencias se realizó utilizando el programa BioEdit (TA Hall, 1999), que consistió en hacer una revisión visual de los cromatogramas y corregir los nucleótidos que apareen superpuestos. Posteriormente se concatenaron las secuencias en un archivo FASTA que facilita el posterior alineamiento y análisis filogenético. Además se eliminaron aquellas secuencias menores a los 500 pares de bases.

Los alineamientos se hicieron en el programa MEGA-5b, utilizando el algoritmo ClustalW1.6 (Larkin el tal, 2007) con los valores de procesamiento estándar (Gap opening penalty = 15, Gap extensión penalti $=6.6$ ).

Elaboración de los árboles filogenéticos. Se utilizó el programa Molecular Evolutionary Genetic AnalysisMEGA-5b (Kumar et al; 2008), con el método de distancia Neighborjoining y el modelo de substitución Kimura 2 parameter (K2P).Se hizo prueba de bootsrapping con mil réplicas.

\section{Resultados y Discusión}

Recolección de muestras. Se colectaron un total de 239 muestras, provenientes de 7lagunas, 2 lagos (Cocibolca y Xolotlán) y del Río San Juan (Tabla 1). De cada espécimen colectado se conserva: aleta pectoral (Centro de Biología Molecular) individuo completo (Bavarian State Collection) fotografías y hojas de campo.

Tabla 1. Muestras colectadas en Lagos y Lagunas de Nicaragua.

\begin{tabular}{|l|c|}
\hline \multicolumn{1}{|c|}{ Lagunas } & $\begin{array}{c}\text { No de Muestras } \\
\text { colectadas }\end{array}$ \\
\hline Tiscapa & 7 \\
\hline Apoyeque & 18 \\
\hline Xiloá & 52 \\
\hline Apoyo & 26 \\
\hline Asososca León & 16 \\
\hline Moyuá & 4 \\
\hline Monte Galán Lago Cocibolca \\
\hline \multicolumn{2}{|c|}{} \\
\hline San Miguelito & 16 \\
\hline San Carlos & 17 \\
\hline
\end{tabular}




\begin{tabular}{|l|c|}
\hline Isletas de Granada & 21 \\
\hline Puerto Díaz & 25 \\
\hline Lago Xolotlán \\
\hline Mateare \\
\hline Río San Juan \\
\hline A 10 km de San Carlos & 12 \\
\hline Total = 239 \\
\hline
\end{tabular}

Extracción de ADN y amplificación por PCR. Se extrajo ADN genómico de 239 muestras, utilizando dos métodos: la extracción orgánica y kit comercial. Con la extracción orgánica se obtuvo ADN genómico del total de las muestras

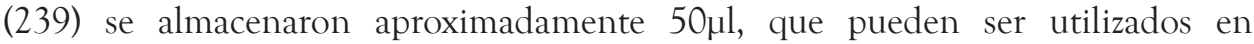
análisis posteriores. Con el kit comercial se extrajo un total de 70 muestras, de las que se conservó $20 \mu \mathrm{l}$. El ADN obtenido por la extracción orgánica resultó de buena calidad, ya que fue de alto peso molecular y las bandas se apreciaron bien definidas. Se realizó las amplificaciones PCR utilizando la enzima del kit Phire® Animal TissueDirectPCR. Se obtiene un producto aproximadamente de $700 \mathrm{pb}, \mathrm{y}$ únicamente bandas específicas.

Secuenciación. Los productos de la PCR se secuenciaron, obteniendo cromatogramas de buena calidad sin gran cantidad de inespecificidad o background. Luego de la secuenciación, el Analizador Genético ABI3130 emite los resultados en archivos de tres diferentes tipos de formatos: archivo AB1, .phd, y archivo SEQ para ser editados utilizando el programa BioEdit. De esta manera, se pudo ver la calidad de las secuencias, y editarlas visualmente.

Análisis de las secuencias del gen COI. De cada una de las secuencias se hizo BLAST, para comprobar que se estaba secuenciando el segmento adecuado del gen COI. La mayoría de las muestras coincidió con secuencias reportadas para especies del género Amphilophus o especies de la familia Cichlidae, específicamente la primera opción de coincidencia fue una secuencia de Amphilophus citrinellus proveniente de un estudio sobre cíclidos en las Antillas (Chakrabarty, 2006,).

Alineamientos. Después del BLAST de las secuencias, se procedió con los alineamientos. Los alineamientos se repitieron varias veces, recortando aproximadamente los primeros 80 y últimos 100 pares de bases, ya que con frecuencia en estas posiciones hay errores de secuenciación. Cada vez que se editaban las secuencias, se tenía que repetir el alineamiento. Como resultado final se obtuvo un alineamiento, en el que no se incluyeron secuencias que diferían del cohorte, y que por lo tanto provocaban la presencia de gaps muy frecuentes o extensos, que pudiesen resultar en "falsos grupos" al momento de elaborar el árbol filogenético.

Arboles filogenéticos. Primero se realizó un árbol, en el que se incluyó a las muestras de todas las localidades (ver Figura 2), además, de un grupo externo (Oreochromis niloticus). Esto para lograr tener una idea general de las relaciones entre las especies. Este grupo de peces desde los primeros intentos de clasificación han sido objeto de discusión, debido a que algunos son muy parecidos morfológicamente y no fue posible diferenciarlos y clasificarlos bajo ese criterio, considerándose que solamente existía una especie y que esta presentaba diferentes formas (Mckaye y Stauffer, 2002). 
En los últimos 10 años se han reportado 8 nuevas especies endémicas y se piensa que son muchas más. El proceso de especiación ha sido muy debatido, ya que estas especies tienen que haber evolucionado en un corto período de tiempo en espacios reducidos, compartiendo sitios de apareamiento y alimentación (Stauffer, McCrary y Black, 2008). Una de las teorías más aceptadas, basada en evidencias geológicas, filogeográficas y de genética poblacional, es que las poblaciones más antiguas se encontraron en el lago de Nicaragua, y a partir de estas se originaron las poblaciones de las lagunas. Primero hubo especiación alopátrica cuando los peces colonizaron las diferentes lagunas y dejaron el lago, posiblemente por fenómenos naturales como huracanes o aves piscívoras o por introducciones humanas, seguido de diversificación temprana dentro de las lagunas y especiación simpátrica causada por adaptaciones sexuales y ecológicas (Elmer et al, 2010a).

La reciente evolución de estas especies y la posibilidad de que algunas todavía estén atravesando un proceso de especiación (Elmer et al, 2010b), además, que ha sido demostrado que más del $50 \%$ de las especies de las diferentes lagunas comparten haplotipos (Barluenga y Meyer, 2004), explica que el gen COI no permita diferenciar a nivel de especie los diferentes grupos. Un ejemplo claro de esto es la proliferación de peces cíclidos en el lago africano Victoria, alrededor de 200 especies endémicos se encuentran ahí a pesar que el lago es reciente, menos de 1 millón de años. A estas especies se les hizo un análisis con marcadores mitocondriales (no COI) y el resultado determinó secuencias casi idénticas, por lo que se interpreta que el complejo de especies en este lago evolucionó en unos cuantos miles de años, un período de tiempo corto comparado con la diversificación de otras especies de vertebrados (Avise, 2000).

En los cíclidos la diferenciación ecológica es evidente y las especies tienen un mecanismo de aislamiento precigótico muy fuerte. Hay algunas que se aparean en espacios cercanos (McKaye, 1980). Ha sido demostrado que la especiación ecológica puede ocurrir mucho más rápido que la evolución de los marcadores genéticos neutros, que no logran detectar estas variaciones. Sin embargo, la ausencia de diferenciación genética (con estos marcadores utilizados) no refuta la especiación ecológica (Elmer et al, 2010b).

En nuestro estudio, excepto los de Xiloá, los especímenes estudiados y analizados en el árbol filogenético no se agrupan siguiendo patrones de localidad o especie (Figura 2). Las relaciones entre los miembros de Midas Cichlidae son complejas (Wilson et al, 2000), y aún cuando se han realizado estudios ecológicos y genéticos, utilizando diferentes marcadores nucleares y mitocondriales, muchas veces la información filogenética de estos no conduce a resultados congruentes. Hay factores relacionados con el muestreo que pueden afectar negativamente los resultados de la investigación como el período de colecta de las muestras, las técnicas que se utilizan para colectarlas y los sitios de muestreo. Es necesario tener conocimiento de lo antes mencionado, ya que es posible que se colecte muestras en un sitio dónde solamente habita una especie, o utilizando artes de pesca inadecuados y no colectar todas las posibles especies de una laguna. Esto último podría explicar porque' los especímenes no se agrupen siguiendo patrones de localidad o especie (Figura 2). 
En el caso de los individuos de Xiloá se observó que los especímenes forman un clado distinto, aunque no se logran agrupar por especie. Ha sido demostrado que la laguna de Xiloá contiene la mayor variación y riqueza alélica (Vivas y Mckaye, 2001). Además, está comprobado que las especies son más parecidas entre sí genéticamente dentro de las lagunas que entre lagunas, por lo tanto se explica que las especies de Xiloá formen un clado separado.

Se debe tomar en cuenta que algunos estudios proponen la especiación basándose en colores en la laguna de Xiloá, ya que hay evidencia que la especies Amphilophus xiloaensis y A. sagittae (genéticamente distintos utilizando marcadores neutros) que presentan forma "normal" y "dorada”, se aparean de acuerdo al color, lo que podría llevar en un futuro a que se convirtieran en especies distintas (Elmer et al, 2009).

De las especies de Apoyo, A. zaliosus aparece como la más cercana al grupo de especies de Xiloá, lo que se explica debido a que ecológica y genéticamente estas lagunas son las más parecidas (Waid et al, 1999). Además, A. zaliosus es la especie más diferenciada (morfológica y genéticamente) en el grupo de Apoyo, por lo que es probable que se separe de los otros grupos de su localidad.

Como se observará en los árboles posteriores, el conjunto de especies del lago de Nicaragua, no forma un grupo monofilético, no se agrupa de acuerdo a su identidad geográfica o taxonómica, además, no se sabe con exactitud cuántas especies del complejo conviven en el lago.

Por otra parte, los especímenes del lago de Managua $(769,765)$ se agrupan con algunos del Lago de Nicaragua $(777,609)$ algo que se espera debido a la antigua conexión entre estos lagos (Villa, 1976). Además, estudiando las especies que lo habitan, A.citrinellus y A.labiatus, se ha demostrado que la diferenciación genética entre estas especies es leve ya que comparten múltiples haplotipos (Elmer et al 2010b).

Figura 2. Árbol Neighbor-Joining basado en el gen Citocromo C oxidasa subunidad I (región mitocondrial). Las distancias evolutivas fueron calculadas utilizando el método Kimura 2 parameter y son unidades expresadas en el número de sustitución de bases por sitio.

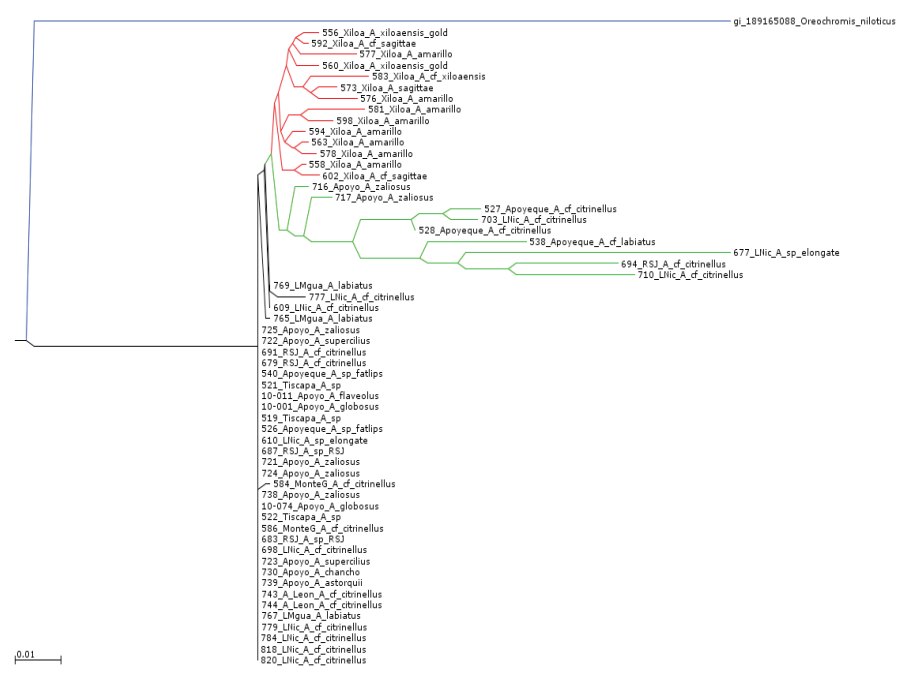


Otra observación importante es en relación al grupo que forman los especímenes del lago de Nicaragua, Río San Juan y laguna de Apoyeque, La relación entre el lago de Nicaragua y Río San Juan se explica a razón del fluctuación genética que pueda ocurrir entre las especies de estos sitios debido a su conexión. La relación con la laguna de Apoyeque es posiblemente debido a que en los individuos que ahí habitan, se ha encontrado solamente el haplotipo más común, procedente de las especies fundadoras del Lago de Nicaragua, y a que la colonización es reciente por lo tanto no ha habido diferenciación de sus ancestros, lo que se soporta debido a que la laguna se formó por una erupción que ocurrió hace tan sólo 1900 años (Geiger, McCrary \& Schiliewen, 2010).

En este estudio empleamos el gen COI para implementar la iniciativa internacional Código de Barras Genético (DNA barcode) encontrando que este gen no ha permitido discriminar entre los miembros del complejo a nivel de especie. En África, se realizaron estudios pilotos con el fin de conocer la utilidad de los "Barcodes" en la identificación de especies de cíclidos, pero los resultados no fueron concluyentes. En un estudio de Código de barras en peces Mexicanos de agua dulce (Valdez et al, 2009), en el que se contó con algunas muestras de peces del complejo, se concluyó que para este caso particular (Midas Cichlidae), el uso de un solo gen (COI) no es suficiente para la identificación de estas especies. Sin embargo, en este estudio se demuestra (Figura 3), que el gen COI permite discriminar entre especies de diferentes localidades, como es el caso de la laguna de Apoyo y Xiloá. Tomando en cuenta el principio de que las especies están más relacionadas entre sí, que entre especies de diferentes lagunas, se elaboró un árbol con las especies de estas localidades.

Se ha demostrado que la ecología y especies que habitan en Xiloá y Apoyo son muy similares. Además, en otros estudios donde se han utilizado marcadores mitocondriales y nucleares las especies de ambas lagunas aparecen formando un mismo grupo (Geiger, McCrary y, Schiliewen, 2010).

Los cíclidos habitan también lagos africanos, en dónde se presenta especiación simpátrica en condiciones similares a las de nuestros lagos. Un ejemplo importante de esta similitud es la evolución convergente que ha ocurrido en el Lago Malawi y Tanganica. Se piensa que las especies limnéticas A .zaliosus de Apoyo y A. sagittae, que son elongadas y ambas con mandíbulas faríngeas papiliformes, han tenido procesos de evolución paralela guiados por fuerzas ecológicas similares. Aunque en el árbol filogenético no se logra apreciar está relación es importante señalar que, así como estas especies están siendo guiadas por fuerzas evolutivas semejantes, puede ser que genes co-específicos estén involucrados en estos procesos y sean compartidos por ambos grupos de especies en Apoyo y Xiloá. 


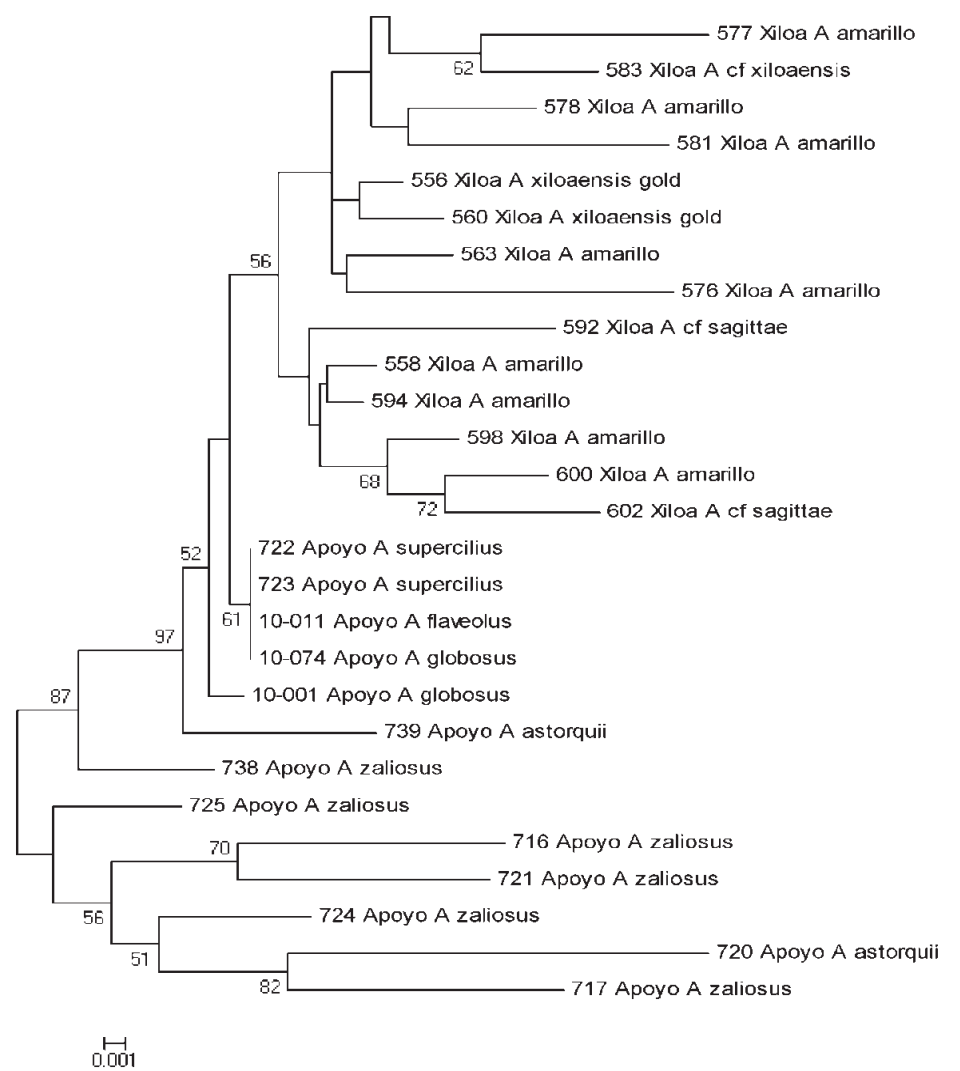

Figura 3. Árbol Neighbor-Joining de las lagunas Xiloá y Apoyo basado en el gen Citocromo $\mathrm{C}$ oxidasa sub unidad I (región mitocondrial). En las ramas se muestra el porcentaje de réplicas en las que los taxa se agruparon en el test de bootstrap (1000 réplicas). Las distancias evolutivas fueron calculadas usando el método P-distancia y son unidades expresadas en el número de sustitución de bases por sitio.

Son muchos los estudios que se han realizado con las especies del Complejo Midas, incluyendo ecología, comportamiento y genéticos. Los estudios filogenéticos son concluyentes en cuanto a utilizar diferentes marcadores para el análisis de las relaciones entre los individuos que habitan las lagunas y a la vez entre los que habitan diferentes lagunas. En la Figura 4, se presenta un árbol delas especies de Asosoca León, Apoyeque, Tiscapa, Monte Galán y Lago de Managua. Se explica que se agrupen de esta forma porque estos reservorios fueron colonizados por especies provenientes del Lago de Nicaragua, y que dichas especies, por su cercanía geográfica compartan información genética.

Las especies de Apoyeque forman un grupo aparte, y por las distancias (longitud de las ramas del arbol) se puede asumir que son especies diferenciadas, es decir que pueden ser diferentes especies del complejo habitando en la laguna. Se observa que hay tipo 'normal' y tipo 'labiatus', y estos forman claramente grupos distintos, este hallazgo es muy importante, pero se necesita demostrar mediante otros estudios la presencia de nuevas especies, principalmente porque esta laguna ha sido poco estudiada. Estos resultados indicarian que ocurre especiación en una laguna de origen reciente (1900 años) y que pueden estar conviviendo al menos dos especies del complejo. 


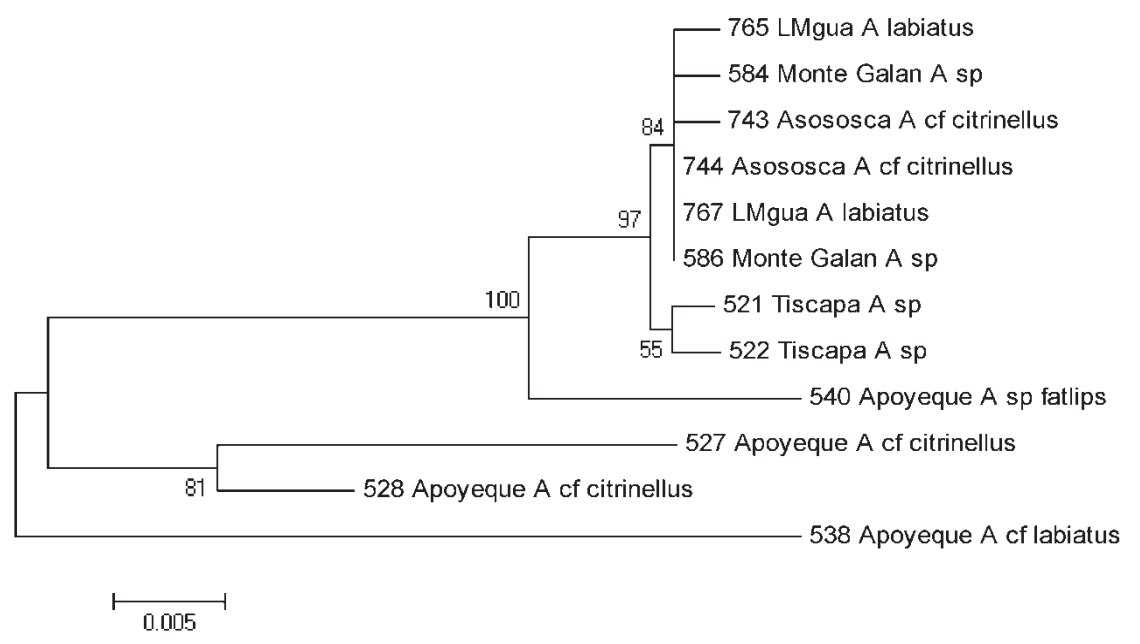

Figura 4. Árbol Neighbor-Joining de las lagunas Monte Galán, Tiscapa, Apoyeque, Asososca León y Lago de Managua basado en el gen Citocromo C oxidasa sub unidad I (región mitocondrial). En las ramas se muestra el porcentaje de replicas en las que los taxa se agruparon en el test de bootstrap (1000 replicas). Las distancias evolutivas fueron calculadas usando el método P-distancia y son unidades expresadas en el número de sustitución de bases por sitio.

En estudios recientes de filogenética (Elmer et al, 2010b y Geiger, McCrary y, Schiliewen, 2010), se ha demostrado la relación cercana entre especies de Asosca Léon y y Monte Galán, además que morfologicamente son las más similares entre sí y similares a la media del compelejo. Estas relaciones se ven reflejadas en el árbol, (Figura 5), y se piensa que debido a sus afinidades geográficas, las especies se encuentran formando un grupo con el Lago de Managua. En el pasado el lago de Managua estuvo conectado con el lago de Nicaragua, luego se separaron y cada uno tiene su propia ictiofauna. Está claro que el lago de Nicaragua contiene a las especies fundadoras del complejo. Sin embargo, se piensa que, aunque se diferenciaron después de la separación, aun comparten información genética y morfología. Se presume que las especies fundadoras de las lagunas Tiscapa, Monte Galán y Asosca León, provenieron del lago de Managua. Las especies de la laguna de Tiscapa aparecen como grupo hermano de las anteriormente mencionadas.

Sin embargo, conviene hacer algunas observaciones adicionales. En el Río San Juan hay posiblemente dos especies, lo que se refleja en el árbol ya que los especímenes 687 y 683 denominados A. sp 'RSJ', forman un grupo aparte. Este grupo aparece como hermano de un grupo combinado de especies del Río San Juan y lago de Nicaragua. En el árbol (Figura 5) se ven muy bien diferenciados dos grandes grupos, que aunque combinados, puede indicar que ya hay una separación clara entre las especies de ambos sitios. 


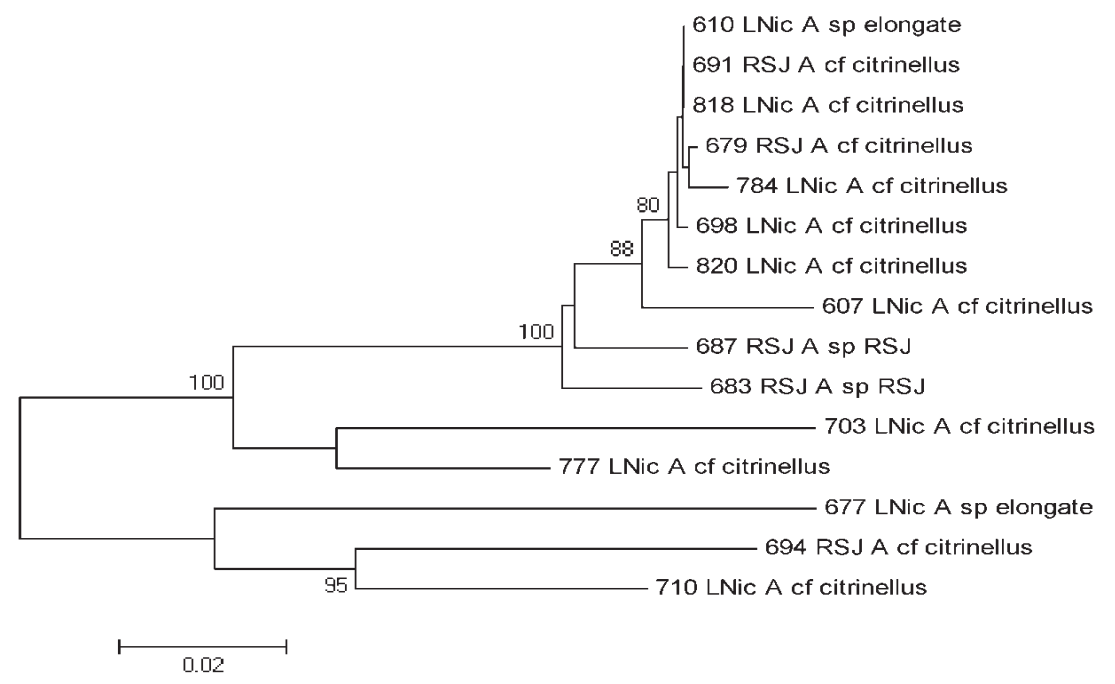

Figura 5. Árbol Neighbor-Joining del Lago de Nicaragua y Río San Juan basado en el gen Citocromo C oxidasa sub unidad I (región mitocondrial). En las ramas se muestra el porcentaje de replicas en las que los taxa se agruparon en el test de bootstrap (1000 replicas). Las distancias evolutivas fueron calculadas usando el método P-distancia y son unidades expresadas en el número de sustitución de bases por sitio.

Nuestro proyecto forma parte de un proyecto más amplio que comprende la creación de un biorrepositorio de la biodiversidad nicaragüense que comprende un archivo de material genético (ADN), tejido, secuencias del gen COI, fotografías, información, taxonómica y de colecta para todos los individuos colectados. Esto se almacena en BOLD Systems ${ }^{2}$, de forma accesible, ordenada y fácil de localizar. Esta es la primera experiencia de este tipo para Nicaragua.

En el sistema BOLD, para cada espécimen se crearon 3 páginas principales para manejar la información: página de información taxonómica y colecta, página de información genética y una página que ubica al espécimen filogenéticamente y presenta estadísticas por taxa. El proyecto, además de ser de gran utilidad para almacenar información completa de las especies, permite relacionar a nuestros especímenes con otros a nivel mundial, y situar a la Biodiversidad de nuestro país en el mapa de la investigación científica.

El presente trabajo de investigación constituye el primer estudio de filogenética molecular utilizando el gen COI y realizado en su totalidad en el país. Se ha logrado confirmar hipótesis planteadas por otros autores y aportar nuevas sobre la compleja situación de los peces cíclidos en Nicaragua, contribuyendo al debate actual de la comunidad científica acerca de la correcta clasificación de la mojarra, sus relaciones filogenéticas y los procesos de especiación de las especies del Complejo.

EL gen COI permitió diferenciar en algunos casos especies de diferentes lagunas como en Xiloá-Apoyo-Apoyeque. Se encontraron dificultades en diferenciar 
especies del Lago Managua, Monte Galán y Asososca León, debido a sus afinidades geográficas y la posibilidad de que la especie fundadora de estas lagunas proviene del Lago Managua. Las especies de la laguna de Tiscapa aparecen como grupo hermano de las lagunas anteriormente mencionadas. Las relaciones entre los peces del complejo Midas Cichlidae son complejas y aún utilizando marcadores moleculares y estudios morfométricos y ecológicos no siempre se obtiene resultados congruentes. El gen COI no permitió identificar los especímenes a nivel de especies, aunque en algunos grupos fue útil para grupos geográficos.

De acuerdo a los análisis realizados, la laguna de Apoyeque puede contener dos especies del complejo: una forma 'normal' y una 'labiatus' (labios pronunciados). Lo mismo sucede en el Río San Juan, donde se identifican especies parecidas a 'citrinellus' y otra posible especie de cuerpo alto y redondeado. En el lago de Nicaragua conviven varias especies, estrechamente relacionadas con las especies del Río San Juan, ya que todavía hay un flujo genético entre ambas localidades.

Por la dificultad del gen de diferenciar a nivel de especie, la falta de agrupamiento en los árboles filogenéticos obedeciendo a localidades o grupos de especies, y tomando en cuenta la reciente creación de las lagunas y su tamaño reducido sin presentar barreras geográficas, se presume que ocurrió y actualmente ocurre un proceso de especiación simpátrica acompañado en algunos casos por evolución paralela convergente.

Urge profundizar estos temas con mas estudios que incluyan el muestro extenso de estas lagunas, ya que debido al difícil acceso a algunas de las lagunas (Apoyeque, Asososca León, Monte Galán y Tiscapa) y a la extensión de los grandes lagos Nicaragua y Managua no se han colectado un número de muestras considerables que pueda conllevar resultados más congruentes, y se ha demostrado que de una localidad a otra varía la información genética de estas especies.

Para obtener información más completa y poder elaborar hipótesis precisas y congruentes, los estudios genéticos, deben ir siempre acompañados por más estudios de ecología y morfología. De igual forma en la actualidad, se debe aprovechar los recursos emergentes como la secuenciación y dirigir las investigaciones a encontrar genes que intervienen directamente en el proceso de especiación-por ejemplo aquellos que intervienen en la visión de los peces y hacen que prefieran aparearse con individuos de un color específico- y a la inferencia de las bases genómicas en la variación fenotípica y ecológica como la morfología y selección de sitios de alimentación y reproducción.

Agradecimientos: Este estudio recibió apoyo financiero del Centro de Biología Molecular de la Universidad Centroamericana. Se agradece el apoyo brindado por la doctora Verónica Díaz (UNAN-León) como asesora y revisora de este trabajo. Además, agradecemos la colaboración entusiasta de los expertos Matthias Geiger (Zoologische Staatssammlung München, Germany) y Jeffrey McCrary (FUNDECI-GAIA, Nicaragua). 


\section{Referencias bibliográficas}

Astorqui, I. (1971) Peces de la cuenca de los grandes lagos de Nicaragua. Rev. Biol. Trop. 19, 7-57.

Ausubel, J; Stoeckle, M \& Waggoner, P. (2005). Barcoding Life, Illustrated. Disponible en sitio web de la Universidad Rockeffeller: http://phe.rockeffeller.edu.

Avise, J. (2000). Philogrography. Harvard University Press. Cambridge, USA.

Azofeifa-Delgado, A. (2006). Uso de marcadores moleculares en platas, aplicaciones en frutales del trópico. Agronomía Mesoamericana. 17(2): 221-242

Chakrabarty,P. (2006). Systematics and historical biogeography of Greater Antillean Cichlidae. Mol. Phylogenet. Evol. 39 (3), 619-627

Barluenga, M. \& Meyer, A. (2004). The Midas cichlid species complex: incipient sympatric speciation in Nicaraguan cichlid fishes. Mol. Ecol. 13, 2061-2076.

Barluenga, M \& Meyer, A. (2010). Phylogeography, colonization and population

history of the Midas cichlid species complex (Amphilophus spp.) in the Nicaraguan crater lakes. BMC Evolutionary Biology 10:326

Barlow, G. W. (1976a). The Midas cichlid in Nicaragua. In Investigations of the ichthyology of Nicaraguan lakes (ed.T. B. Thorson), pp. 333-358. Lincoln, NE: University of Nebraska Press.

Barlow, G.W \& Munsey, J.W. (1976). The red devil-Midas-arrow cichlid species complex in Nicaragua. In: Thorsen, T.B. (Ed.), Investigations of the Ichthyo fauna of Nicaraguan Lakes. University of Nebraska Press, Lincoln, NB, pp. 359-369.

Barluenga, M; Stolting, K; Salzburger, W; Muschik, M \& Meyer, A. (2006).

Sympatric speciation in Nicaraguan crater lake cichlid fish. Nature 439, 719-723.

Basic Local Alignment Search Tool. Disponible en sitio web: http://blast.ncbi.nlm. nih.gov/Blast.cgi

Consortium for the Barcode of life (CBOL). Disponible en sitio web:http://www. barcoding.si.edu/whatis.html

Edgar, R. (2004), MUSCLE: multiple sequence alignment with high accuracy and high throughput, Nucleic Acids Research 32(5), 1792-97.

Elmer, K; Lehtonen, T; \&Meyer, A. (2009). Color assortative mating contributes tosympatric divergence of Neotropical cichlid fishes. Evolution 63, 27502757.

Elmer, K; Fan, S; Gunter, H; Jones, J; Boekhoff, S; Kuraku, S\& Meyer, A. (2010a). Rapid evolution and selection inferred from the transcriptomes of sympatric crater lake cichlid fishes. Mol. Ecol. 19(Suppl.1), 197-211

Elmer, K; Kusche, H; Lehtonen, T \& Meyer, A. (2010b). Local variation and parallel evolution: morphological and genetic diversity across a species complex of neotropical crater lake cichlid fishes. Phil. Trans. R. Soc. B 365, 1763-1782.

Frézal, L \& Leblois , R. (2008). Four years of DNA barcoding: Current advances and prospects, Infect. Genet. Evol.

Geiger, M; McCrary, J \& Schiliewen, U. (2010). Not a simple case - A first comprehensive phylogenetic hypothesis for the Midas cichlid complex in Nicaragua (Teleostei: Cichlidae: Amphilophus) Molecular Phylogenetics and 
Evolution, 56 (3), pp. 1011-1024.

Hall, B. (2001). Phylogenetic Trees Made Easy. Sinauer Associates, Inc.

Hall, TA. (1999) Nucleic Acids Symposium Series, Vol. 41 pp. 95-98.

Hillis, D; Mortiz, C \& Mable, B. (Editores). (1996). Molecular Systematics. Second Edition, Sinauer Associates, Inc. Massachusetts, USA.

Huertas, M. (2004). Curso sobre técnicas en Biotecnología. CNU, UNAN-León. Nicaragua.

Klingenberg, C; Barluenga, M. \& Meyer, A. (2003). Body shape variation in cichlid fishes of the Amphilophus citrinellus species complex. Biol. J. Linn. Soc. 80, $397-408$.

Kocher, T. (2004). Adaptive evolution and explosive speciation: the cichlid fish model. Nat. Rev. Genet. 5, 288-298.

Kess, J; Wurdack, K; Zimmer, E; Weigt, L \& Jansen, D. (2005). Proc Natl Acad Sci USA 102: 8369-8374

Lahaye, $R$ et al. (2008). DNA barcoding the floras of biodiversity hotspots. PNAS. 105 (8) 2923-2928.

Larkin, M; Blackshields, G; Brown, N; Chenna, R; McGettigan, P; McWilliam, H; Valentin, F; Wallace, I; Wilm, A; Lopez, R; Thompson, J; Gibson, T; \& Higgins D. (2007). ClustalW and ClustalX version 2. Bioinformatics 23(21): 2947-2948)

Lopera-Barrero, N; Povh, J; Ribeiro, R; Gomes, P; Jacometo, C \& da Silva, T. (2008). Comparación de protocolos de extracción de ADN con muestras de aleta y larva de peces: extracción modifi cada con cloruro de sodio. Cien. Inv. Agr. 35(1): 77-86.

Kumar, S et al(2008). MEGA: A biologist-centric software for evolutionary analysis of DNA and protein sequences. Brief in Bioinformatics 9: 299 - 306.

Maynard-Smith, J. (1966) Sympatric speciation. American Naturalist. 100: 637-650

McKaye, K.R.(1980). Seasonality in habitat selection by the gold color morph of Cichlasoma citrinellum and its relevance to sympatric speciation in the family Cichlidae. EnvIRON. Biol. Fishes 5, 75-78.

McKaye, K, Stauffer, Jr. J ; van den Berghe, E; Vivas, R; Lopez-Perez, L; McCrary, J; Waid, R; Konings, A; Lee, W \& Kocher, T. (2002). Behavioral, morphological and genetic evidence of divergence of the Midas cichlid species complex in two Nicaraguan crater lakes. Cuadernos de Investigación de la UCA 12, 19-47.

Meyer, A. (1990b). Morphometrics and allometry in the trophically polymorphic cichlid fish, Cichlasoma citrinellum: alternative adaptations and ontogenetic changes in shape. J. Zool. 221, 237-260.

Miklos, D; Freyer, G \& Crotty, D. (2003). DNA sequencing en DNA Science: A first course. Second Edition. Cold Spring Harbor Laboratory Press

New England Biolabs. Manual Files Kit Phire ${ }^{\circledR}$ Animal Tissue Direct PCR

Disponible en sitio web: http://www.neb.com/nebecomm/ManualFiles/ manualF-140.pdf

Otte, D. \&Endler, J.A. eds. (1989). Speciation and its consequences. Sinauer Ass., Sunderland, Mass.

Pevsner, J. (2010). Multiple Sequence Alignment en Bioinformatics and Functional Genomics. Second Edition. Wiley Interscience Press. 
Purvis, Andy \& Hector, Andy. (2000). Getting the mesuare of biodiversity.Nature: vol 405:212.219

Rueda , R. (2007). Recopilación de la información sobre la biodiversidad de Nicaragua. Universidad Nacional Autónoma de Nicaragua-León. Norwegian Ministry of Foreign Affairs. Inbio- Costa Rica.

Stauffer, Jr. J \& McKaye, K. (2002). Description of Three New Species of Cichlid Fishes (Teleostei: Cichlidae) from Lake Xiloá, Nicaragua. Cuadernos de Investigacion de la U.C.A. 12, 1-18.

Stauffer Jr. J; McCrary, J \& Black, K. (2008). Three new species of cichlid fish (Teleostei: Cichlidae) in Lake Apoyo, Nicaragua. P. Biol. Soc. Wash. 121, $117-129$.

Stauffer Jr. J; Geiger, M; \& McCrary, J. (2010). Description of two new species of the Midas cichlid complex Telostei:Cichlidae) from Lake Apoyo, Nicaragua. Proc. Biol. Soc. Wash. 123(2): 159-173.

Templenton, A.P. (1980). The theory of speciation via the founder principle. Genetics 94: 1011-138

Valdez-Moreno,M; Ivanova , N; Elias-Gutierrez, M; Contreras-Balderas \& Hebert, P. (2009).Probing diversity in freshwater fishes from Mexico and Guatemala with DNA barcodes. Journal of Fish Biology 74, 377-402

Villa, J. (1976). Ichthyology of the lakes of Nicaragua: historical perspective. In Investigations of the ichthyology of Nicaraguan lakes (ed. T. B. Thorson), pp. 101-113. Lincoln, NE: University of Nebraska Press.

Villa, J. (1982).Peces Nicaragüenses de agua dulce. Colección Cultural. Serie Geografía y Naturaleza.

Vivas, R. \& McKaye, K.(2001). Habitat selection, feeding ecology, and fry survivorship in the Amphilophus citrinellus species complex in Lake Xiloá. J. Aquacult. Aq. Sci. IX, 32-48.

Waid, R; Raesly, R; McKaye, K \& McCrary, J.(1999).Zoogeografía 1ctica de lagunas cratéricas de Nicaragua.

Encuentro 51, 65-80.

Wilson, A; Noack-Kunnmann, K \& Meyer, A.(2000). Incipient speciation in sympatric Nicaraguan crater lake cichlid fishes: sexual selection versus ecological diversification. Proc. R. Soc. Lond. 267, 2133-2141. 